\title{
Renal lymphoma: an unusual cause of extrahepatic biliary obstruction
}

\author{
Z Abbas, DA Johnston, FE Murray
}

\begin{abstract}
Summary
This report describes a case of lymphoma arising in a kidney subjected to previous pyelolithotomy, lithotripsies and percutaneous nephrolithotomy. The tumour had invaded the pancreas and duodenum, resulting in extrahepatic biliary and gastric outlet obstructions. Fine-needle apiration cytology guided by computed tomography failed to suggest the diagnosis which was confirmed only on laparotomy and open biopsy. Drainage procedures were performed to relieve the obstructions. To our knowledge this is the first case report of renal lymphoma presenting with extrahepatic biliary obstruction.
\end{abstract}

Keywords: non-Hodgkin's lymphoma, biliary obstruction, lithotripsy

Extrahepatic biliary obstruction is an uncommon feature of non-Hodgkin's lymphoma with reported incidences of $1.6 \%^{1}$ to $5.5 \% .^{2} \mathrm{~Pa}-$ tients with non-Hodgkin's lymphoma who develop obstructive jaundice usually have either primary disease of the gastrointestinal tract or widespread disease with lymph node involvement along the biliary tree. We report an unusual case of renal lymphoma presenting with obstructive jaundice.

\section{Case report}

A 49-year-old man was admitted to hospital in January 1994 with a three-week history of obstructive jaundice associated with nausea and vomiting. He had previously undergone a panproctocolectomy with ileostomy, because of intractable ulcerative colitis in 1965 and a right pyelolithotomy for a staghorn calculus in 1983. Recurrent right-sided calculi had been treated with lithotripsy in 1985 and again in 1988. In 1990 right percutaneous nephrolithotomy was performed, despite which he had repeated attacks of right loin pain associated with urinary tract infections.

On examination, he was deeply jaundiced with scratch marks. The gallbladder was palpable. There were no palpable lymph nodes. Pertinent laboratory data included total bilirubin $191 \mu \mathrm{mol} / 1$; alanine aminotransferase $653 \mu \mathrm{l}$; alkaline phosphatase $564 \mu \mathrm{l}$; gammaglutamyl transferase $563 \mu \mathrm{l}$; albumin $40 \mathrm{~g} / \mathrm{l}$; creatinine $126 \mu \mathrm{mol} / 1$; full blood count was normal. The urine was positive for bilirubin. Ultrasonography of the abdomen demon- strated a dilated biliary tree, enlarged gallbladder and a large mass arising from the right kidney. A computed tomography (CT) scan confirmed the ultrasound findings and demonstrated the mass distorting the right kidney, displacing the inferior vena cava and head of pancreas anteriorly and extending into the right lobe of liver. Moreover there was a loss of definition between the mass and the aorta. Fine-needle aspiration cytology of the mass reported a large number of inflammatory cells including neutrophils, plasma cells, and lymphocytes. Endoscopic retrograde cholangiopancreatography was prevented by extrinsic compression at the junction of first and second part of duodenum, which hindered passage of the scope into the second part of duodenum.

Laparotomy revealed a large unresectable renal mass which had infiltrated the head of pancreas and duodenum. The biliary and gastric outlet obstructions were managed by cholecystojejunostomy and gastrojejunostomy. Biopsy of the renal mass showed high grade $T$ cell lymphoma of immunoblastic type. The patient was treated with cyclophosphamide, doxorubicin, vincristine and prednisolone (CHOP regimen). Parenteral nutrition was initiated. His liver function tests returned to almost normal and a repeat CT scan after three weeks showed a $50 \%$ reduction of the tumour size. He was given two more courses of CHOP but unfortunately there was no further reduction of tumour mass. Despite a change in chemotherapy to mitoxantrone and iphosphamide the patient died, six months after definitive diagnosis.

\section{Discussion}

We describe a patient who presented with obstructive jaundice which is a most unusual manifestation of non-Hodgkin's lymphoma. A Medline search on the subjects of lymphoma, cholestasis and extrahepatic bile duct obstruction revealed 29 reports of patients with gastrointestinal lymphomas or widespread disease at the time of presentation (table). We could not find any previous report of renal lymphoma causing obstructive jaundice.

Our patient had a history of intractable ulcerative colitis for which panproctocolectomy had been performed in 1965. Extraintestinal lymphomas have been found to occur with increased frequency in patients with inflammatory bowel disease, ${ }^{11}$ possibly as a result of primary immunological defects, im- 
Table Extrahepatic biliary obstruction by non-Hodgkin's lymphomas

\begin{tabular}{lll}
\hline Site of lymphomatous involvement & $\begin{array}{l}\text { Patients } \\
(n)\end{array}$ & Ref \\
\hline Pancreas & 7 & 3 \\
& 3 & 2 \\
& 3 & 4 \\
Small intestine & 1 & 5 \\
Stomach & 1 & 6 \\
Gastroduodenal & 1 & 7 \\
Periampullary region & 1 & 1 \\
Common bile duct & 1 & 7 \\
& 1 & 8 \\
Widespread disease with & 1 & 1 \\
lymph nodes involvement & 1 & 9 \\
& 2 & 1 \\
& 2 & 2 \\
& 2 & 5 \\
\end{tabular}

munosuppressive therapy or frequent exposure to X-rays. ${ }^{12}$ Our patient did not have any residual inflammatory bowel disease but he had frequently been exposed to X-rays to investigate urinary tract infections associated with renal calculi. His right kidney was also diseased and damaged, and had been subjected to multiple manipulations for recurrent calculi. In addition, lithotripsy was performed twice. However, we could find no report of any association between lithotripsy and possible tumourogenesis, and any possible causative role of lithotripsy must remain purely speculative.

Our patient had a high-grade lymphoma. These aggressive lymphomas respond to aggressive treatment. Complete remission may

1 Boddie AW Jr, Eisenberg BL, Mullins JD, Schlichtemeie AL. The diagnosis and treatment of obstructive jaundice secondary to malignant lymphoma: a problem in multidisciplinary managememt. I Surg Oncol 1980; 14: 111-23.

2 Ehrlich AN, Stalder G, Geller W, Sherlock P. Gastrointestinal manifestations of malionant lymphoma Gastroenterology 1968; 54: 1115-21.

3 Tuchek JM, De Jong SA, Pickleman J. Diagnosis, surgical intervention and prognosis of primary pancreatic intervention and prognosis of p

4 Swartz TR, Ritchie WG. Bile duct obstruction secondary to lymphomatous involvement of pancreas. $\mathcal{f}$ Clin Ultrasound

5 Young IF, Roberts-Thomson IC, Sullivan JR. Histiocytic ymphoma presenting with extrahepatic biliary obstruction: a report of three cases. Aus NZ F Surg 1981; 51: 181 -3.

6 Halline A, Lerios M, Melissas J, Segal I, Grieve TP. Primary lymphoma of the small bowel with obstructive jaundice an pancreatitis. A case report. $S$ Afr Med f 1987; 72: 61-2.

7 Radhakrishnan S, Al Nakib B, Al Liddawi H, Al Ruwaih A Primary gastrointestinal lymphoma complicated by common bile duct obstruction: report of two cases. $A m \mathcal{F}$ Gastroenterol 1986; 81: 691-4.

8 Bassek L, Orron D. Non-Hodgkin's lymphoma presenting as periampullary mass with obstructive jaundice. $\mathcal{f}$ Comput Tomogr 1986; 10: 89-92.

\section{Hepatobiliary manifestations of lymphoma}

- hepatic infiltration by lymphoma

- hepatic granulomatous disease

- fulminant hepatic failure

- biliary tract obstruction

\begin{tabular}{|l|}
\hline Learning/summary points \\
\hline $\begin{array}{l}\text { - lymphoma causing biliary tract obstruction is } \\
\text { unusual } \\
\text { such obstruction has not been previously } \\
\text { described }\end{array}$ \\
\hline
\end{tabular}

be expected in $60-80 \%$ of cases with intensive combination regimens and long-term disease from survival in $30-50 \%$ cases. ${ }^{13}$ Our patient $\mathrm{N}$ was given CHOP regimen which has been shown to be better than new second and third generation regimens. ${ }^{14}$ Unfortunately he had 을 many poor prognostic factors including large tumour size and ' $T$ ' cell type. ${ }^{15}$ Moreover, renal lymphomas carry a poor prognosis due to rapid spread, and survival for more than one year is rare. ${ }^{16}$ Our patient survived only six months after diagnosis. He presented with extrahepatic biliary obstruction which may also be considered as a poor prognostic sign as all patients with non-Hodgkin's lymphoma who presented with obstructive jaundice had poor long term survival.

9 Nguyen GK. Primary extranodal non-Hodgkin's lymphoma of extrahepatic bile ducts. Report of case. Cancer 1982; 50: 2218-22.

10 Feller E, Schiffman FJ. Extrahepatic biliary obstruction of lymphoma. Arch Surg 1990; 125: $1507-9$.

11 Greenstein AI, Gennuso R, $2914-21$.

12 Greenstein AJ, Mullin GE, Strauchan JA, et al. Lymphoma in inflammatory bowel disease. Cancer 1992; 69: 1119-23. 13 Armitage JO. Treatment of non-Hodgkin's lymphoma. $N$ Engl f Med 1993; 328: $1023-30$.

14 Fisher RI, Gaynor ER, Dahlberg S, et al. Comparison of a standard regimen (CHOP) with three intensive chemotherapy regimens for advanced non-Hodgkin's lymphoma. $N$ Engl f Med 1993; 328: $1002-6$.

15 Lippman SM, Miller TP, Spier CM, Slymen DJ, Grogan TM. The prognostic significance of immunotype in diffuse large cell lymphoma: a comparative study of T-cell and Bcell phenotype. Blood 1988; 72: 436-41.

16 Kandel LB, McCullough DL, Harrison LH, et al. Primary renal lymphoma. Does it exist? Cancer 1987; 60: 386-91. 